\title{
BAGAIMANAKAH PROSES BELAJAR ANAK TUNARUNGU DAN ANAK AUTISME?: STUDI KASUS DI SALAH SATU SLB DI INDRAMAYU
}

\author{
Tating Nuraeni, Laesya Nurhayatul Mardiah ${ }^{2}$ \\ ${ }^{1,2)}$ Universitas Wiralodra, Jl. Ir. Djuada Km. 3 Indramayu, tatingnuraeni@ gmail.com, \\ icalaesya85@gmail.com
}

Diterima 25 Januari 2020, disetujui 16 april 2020, diterbitkan 30 april 2020

pengutipan: Nuraeni, T \& Mardiah, L.N. (2020). Bagaimanakah proses belajar anak tunarungu dan anak autisme?: Studi kasus di salah satu SLB di Indramayu. Gema Wiralodra, Vol 11, No 1, Hal 133-142, April 2020

\begin{abstract}
ABSTRAK
Penelitian ini dilakukan dengan tujuan untuk mengetahui bagaimana proses belajar yang tepat pada anak berkebutuhan khusus, khususnya anak tunarungu dan autis. Penelitian ini dilakukan di di salah satu SLB yang adi di Indramayu. Penelitian ini menggunakan pendekatan kualitatif. Teknik pengumpulan data yang dilakukan yakni pengamatan (observation), pengamatan terlibat (participant observation), dan wawancara secara mendalam (indepth interview). Analisis data yang digunakan menggunakan analisis data yang diadopsi oleh Miles and Huberman yang terdiri dari pengumpulan data, reduksi data, penyajian data dan penarikan kesimpulan. Setelah melakukan penelitian ini, didapatkan hasil bahwa terdapat perbedaan proses belajar antara anak tunarungu dan autis. Pada anak tunarungu, metode yang tepat biasanya menggunakan gambar atau objek agar mereka dapat mudah memahaminya. Akan tetapi, pada anak autis biasanya pembelajaran bukan ditekankan pada suatu materi tertentu akan tetapi lebih pada agar mereka dapat berinteraksi dan bersosialisasi dengan orang lain.
\end{abstract}

Kata Kunci: Proses Belajar, SLB, Tunarungu, dan Autis

\begin{abstract}
This research was conducted with the aim to find out how the right learning process in children with special needs, especially deaf and autistic children. This research was carried out in one of the high schools in Indramayu. This research uses a qualitative approach. Data collection techniques used are observation (observation), observation involved (participant observation), and in-depth interviews (indepth interview). Analysis of the data used uses data analysis adopted by Miles and Huberman consisting of data collection, data reduction, data presentation and drawing conclusions. After conducting this research, the results show that there are differences in the learning process between deaf and autistic children. In children who are deaf, the right method is usually to use images or objects so that they can easily understand them. However, in children with autism learning is usually not emphasized on a particular material but rather so that they can interact and socialize with others.
\end{abstract}

Keywords: Learning Process, SLB, Deaf, Autistic

Diterbitkan oleh:

Universitas Wiralodra

Jln. Ir. H. Juanda Km 3 Indramayu, Jawa Barat 


\section{PENDAHULUAN}

Proses pembelajaran adalah proses yang menggabungkan dua konsep antara belajar dan mengajar (Khalil \& Elkhider, 2016). Menurut Harold Spears (1955) learning is shown by observe, to read, to imitate, to try something them selves, to listen, to follow direction [pembelajaran ditunjukan dengan mengamati, membaca, meniru, mencoba sesuatu diri mereka sendiri, mendengarkan, mengikuti arahan]. Dengan kata lain, belajar adalah upaya yang dilakukan oleh individu dengan segala aktivitasnya baik membaca, meniru, melihat, dan berani mencoba hal-hal yang telah dipelajari dengan tujuan dapat memberikan tanggapan positif serta mendapatkan perubahan baik tingkah laku, cara berpikir, maupun pengetahuan dan keterampilannya.

Masing-masing anak memiliki proses belajar atau cara belajar yang berbeda satu dengan yang lain (Darling-Hammond, L., Flook, L., Cook-Harvey, C., Barron, B., \& Osher, D. (2020). Ada anak yang akan lebih mudah menyerap pembelajaran atau informasi dengan mendengarkan, ada pula dengan hanya membaca, ada pula yang menggunakan gambar, dan masih banyak lagi. Setiap anak memiliki cara belajar tersendiri, baik pada anak yang normal maupun pada anak berkebutuhan khusus (Wang, 2009). Menurut Depdiknas (2004: 2), anak berkebutuhan khusus (ABK) adalah anak yang secara signifikan mengalami kelainan atau penyimpangan (fisik, mental-intelektual, sosial, emosional) dalam proses pertumbuhan atau perkembangannya dibandingkan dengan anakanak lain seusianya sehingga mereka memerlukan pelayanan pendidikan khusus. Oleh karena itu, akan ada perbedaan proses belajar atau cara belajar anak berkebutuhan khusus dengan anak pada umumnya.

Banyak penelitian yang memetakan berkaitan dengan cara belajar anak berkebutuhan khusus. Nugroho \& Mareza (2016) dalam penelitiannya menyimpulkan bahwa pendidikan inklusif merupakan salah alternative pembelajaran yang bisa dilakukan pada anak berkebutuhan khusus (Dermawan, 2013). Pembelajaran diberikan secara indifidual yang dikelompokan atas dasar kelas sesuai bagian ketunaannya. Dengan tenaga guru Pendidikan khusus terdiri dari guru khusus berijasah S1 PK/PLB dan S1 Matapelajaran. Berdasarkan hasil 
penelitian, Sudirman, S., Senjaya, A. J., \& SW, P. E (2017) diperoleh gaya belajar siswa tunagrahita ringan pada materi perkalian di sekolah yakni $25 \%$ bertipe visual dan $75 \%$ bertipe kinestetik. Adapun, gaya belajar siswa tunagrahita ringan pada materi perkalian di rumah yakni $25 \%$ bertipe visual, $25 \%$ bertipe auditorial, dan 50\% bertipe kinestetik. Buli-Holmberg, J., \& Jeyaprathaban, S (2016). Penelitian ini menyimpulkan bahwa praktik yang bervariasi dan fleksibel di kelas telah memenuhi semua kriteria yang dicatat oleh para peneliti dan memenuhi persyaratan pembelajaran yang diperlukan anak-anak dengan kebutuhan khusus. Sedangkan empat praktik lainnya hanya melayani anak-anak dengan kebutuhan khusus sampai batas tertentu. Studi ini menyatakan bahwa ada kekurangan keahlian dari pihak guru umum untuk menyampaikan proses belajar mengajar yang disesuaikan dalam praktik ruang kelas yang inklusif. Studi ini menyiratkan kebutuhan untuk membangun kompetensi pada bagian dari guru umum dan menyediakan interaksi belajar-mengajar yang diperlukan, dukungan dan adaptasi dalam semua jenis praktik inklusif.

Berdasarkan hasil penelitian-penelitian yang disebutkan diatas menunjukkan bahwa anak yang bekebutuhan khusus memiliki gaya belajar yang berbeda-beda. Oleh karena itu, proses pembelajarannya harus bersifat inklusif. Namun, jika kita melihat hasil penelitian yang ada masih sedikit yang menjelaskan secara deskriptif bagaimana proses pembelajaran pada anak tunarungu dan autisme. Oleh sebab itu, penelitian ini bertujuan untuk mendeskripsikan proses pembelajaran pada anak berkebutuhan khusus, seperti anak tunarungu dan autis. Meliputi bagaimana cara mereka belajar dan metode s apa yang cocok guna mendukung proses pembelajaran mereka.

\section{METODE PENELITIAN}

Partisipan yang terlibat dalam penelitian ini sebanyak 54 anak yang bersekolah di salah satu SLB yang ada di Indramayu. Subjek terdiri dari laki-laki dan perempuan dari berbagai usia sekolah dimulai dari TK, SD, SMP, sampai dengan SMA. Ada 7 anak pengidap autisme. Pendekatan penelitian menggunaka kualitatif dengan desain case study. Selanjutnya teknik pengumpulan data yang

Diterbitkan oleh:

Universitas Wiralodra

Jln. Ir. H. Juanda Km 3 Indramayu, Jawa Barat 
lazim pada metode ini ialah pengamatan (observation), pengamatan terlibat (participant observation), dan wawancara secara mendalam (indepth interview).

Proses belajar adalah suatu proses interaksi antara siswa dengan pengajar dan sumber belajar dalam suatu lingkungan dan merupakan bentuk bantuan pengajar supaya bisa terjadi proses mendapat pengetahuan.Oleh karena itu untuk mengetahui ada atau tidaknya perbedaan proses belajar anak-anak yang bersekolah di SLB dengan anak-anak pada umumnya dilakukanlah penelitian ini. Metode yang digunakan dalam penelitian ini adalah metode kualitatif dengan pendekatan pengamatan (observation), pengamatan terlibat (participant observation), dan wawancara secara mendalam (indepth interview). Pengamatan (observation) dilakukan dengan cara mengamati anak-anak yang bersekolah di SLB B Mutiara Hati Indramayu dimulai dari cara mereka beriinteraksi, cara mereka menyelesaikan suatu masalah, sampai dengan cara mereka memahami suatu hal. Pengamatan terlibat (participant observation) dilakukan dengan cara mengamati secara langsung dan ikut serta menemani anak-anak di sekolah tersebut dalam mewarnai gambar yang telah disediakan, kamipun ikut serta mengawasi dan membantu mereka dalam mewarnai maupun menuliskan nama mereka pada gambar tersebut. Sedangkan, wawancara secara mendalam (indepth interview) dilakukan dengan cara mewawancarai guru-guru yang mengajar di SLB tersebut guna melengkapi data-data yang diperoleh. Selain itu juga wawancara juga dilakukan pada anak-anak tersebut, guna mengetahui bagaimana cara mereka dalam merespon apa yang mereka tanggap.

\section{TEMUAN PENELITIAN DAN PEMBAHASAN}

\section{Temuan Penelitian}

\section{Proses Belajar Anak Tunarungu}

Anak-anak tunarungu di sekolah tersebut cenderung lebih mudah memahami suatu hal dengan menggunakan objek yang telah dilabeli nama terlebih dahulu. Pada anak tunarungu akan sulit mengerti sesuatu hal yang baru yang tak pernah ia ketahui sebelumnya. Contohnya, anak tunarungu tidak akan mengetahui bahwa gelas adalah gelas, sebelum ia memiliki pembendaharaan kata gelas terlebih dahulu. Ini juga berlaku untuk sesuatu yang lain, seperti mereka tidak akan bisa 
menyebut orang berlari sebelum mereka mendapatkan perbendaharaan kata berlari.

Terlepas dari semua itu, pada anak tunarungu yang terganggu hanya saraf pendengarannya saja. Hal ini menyebabkan tingkat kepandaian intelektualnya sama saja dengan anak pada umumnya. Hanya yang membedakan pada anak tunarungu proses dia belajar lebih menggunakan media objek, gambar, vidio, dan tulisan, dari pada menggunakan kata-kata atau metode ceramah. Menurut penelitian yang dilakukan oleh Dermawan (2013) di SLB PKK Bandar Lampung strategi pembelajaran atau metode pembelajaran yang tepat bagi anak tunarungu adalah menggunakan strategi deduktif, induktif, heuristic, ekspositorik, klasikal, kelompok, individual, kooperatif, dan modifikasi perilaku.

Apabila siswa tuna rungu tidak mampu memahami suatu hal sedangkan mereka mempunyai keinginan mengetahui hal tersebut, dan dengan segala cara mereka belum bisa memahami hal tersebut. Pada puncaknya mereka akan frustasi dan meledak dalam kemarahan.

\section{Proses Belajar Anak Autisme}

Pada anak-anak yang mengidap autisme cenderung memiliki kemampuan yang berbeda-beda dari satu anak dengan anak yang lain meskipun mereka berada di kelas yang sama ataupun memiliki usia yang sama sekalipun. Di SLB B Mutiara Hati sendiri terdapat beberapa anak autisme meskipun mereka berada di dalam kelas yang sama dan usia yang sama tetapi kemampuan mereka berbedabeda. Ada yang mampu mengucapkan beberapa kata walaupun tidak jelas, adapula yang tidak mampu mengucapkan satu patah kata pun. Selain itu juga ada yang mampu mewarnai dengan cukup baik meskipun pemilihan warnanya kurang tepat, ada pula yang tidak dapat mewarnai sama sekali. Ada juga yang dapat menulis walaupun harus dibacakan satu-satu susunan hurufnya, ada juga yang harus dituliskan terlebih dahulu kemudian ia tiru, ada juga yang hanya bisa membuat benang-benang kusut bahkan tidak bisa walaupun hanya sekedar membuat garis lurus saja.

Hal itu dikarenakan, tingkat kemampuan anak autisme baik itu kemampuan verbal maupun motorik tidak dipengaruhi oleh usia tetapi lebih ke tingkat atau derajat penyakit autisme yang diidap. Pembelajaran yang diberikan pun tidak 
dapat dipukul sama rata dengan anak-anak pada umumnya. Hal itu dikarenakan mereka membutuhkan penanganan khusus serta pembelajaran yang sesuai dengan tingkat kemampuan mereka. Anak-anak autisme sering kali cepat bosan dengan suatu pembelajaran. Mood mereka pun dapat berubah dengan cepat, oleh sebab itu ada baiknya anak-anak yang mengidap autisme lebih baik disekolahkan disekolah khusus.

Pada anak autisme sendiri, sebenarnya sekolah bukan untuk mengejar nilai atau suatu target pengetahuan tertentu. Akan tetapi lebih ke bagaimana cara anak tersebut dapat bersosialisasi dan berinteraksi dengan orang lain. Oleh karena itu, ada baiknya orang tua menyekolahkan anaknya ke SLB ketika ia mengetahui bahwa anaknya mengalami suatu gangguan bukan ketika sang anak memasuki usia tertentu. Menurut penelitian yang dilakukan oleh Amalia \& Vidya (2018) problematika anak autisme adalah komunikasi dan sosialisasi. Oleh karena itu, merupakan suatu hal yang fatal jika orang tua dari anak autisme lebih memprioritaskan hal-hal yang bersifat akademik. Menurut mereka strategi atau metode pembelajaran yang tepat bagi anak autisme adalah pembelajaran yang bermakna secara emosional sehingga dapat meningkatkan kemampuan anak autisme dalam berkomunikasi dan berinteraksi dengan orang lain.

\section{Pembahasan}

Hasil temuan penelitian ini selaras dengan penelitiannya Handayani (2017) menyatakan bahwa Penggunaan Simulation Based Learning pada mata pelajaran Bahasa Indonesia materi dongeng sangat diperlukan bagi anak tunarungu. Anak tunarungu merupakan seseorang yang kehilangan kemampuan mendengar baik sebagian atau seluruhnya yang diakibatkan oleh tidak berfungsinya sebagian atau seluruh alat pendengaran sehingga mengalami kesulitan dalam berkomunikasi baik dengan atau tanpa menggunakan alat bantu mendengar (Handayani, 2017). Akibat ketunarunguan yang dialami berdampak pada kehidupan sehari-hari yang kompleks sehingga membutuhkan layanan pendidikan khusus (Handayani, 2017). Akibat gangguan pendengaran yang dialami, anak tunarungu bergantung pada indera penglihatannya untuk memahami lingkungan sekitar (Handayani, 2017). Penggunaan Simulation Based Learning dapat membantu anak tunarungu untuk 
memahami dongeng (Handayani, 2017). Simulation Based Learning sesuai untuk anak tunarungu karena membawa situasi nyata ke dalam situasi tiruan dalam kegiatan pembelajaran di kelas sehingga anak akan berperan aktif sebagai simulator dengan memerankan instruksi - instruksi yang diberikan guru dan informasi yang diperoleh akan lebih bermakna karena anak melakukannya secara langsung sehingga anak dapat mengemukakan pendapat dan pikirannya yang bisa mempermudah tercapainya tujuan pembelajaran (Handayani, 2017). Selain itu menurut Sarbani (2014) Agar proses pembelajaran pada anak tunarungu dapat berjalan secara efektif maka terlebih dahulu guru harus menguasai materi yang akan diajarkan. Kemudian guru menyusun strategi pembelajaran dengan dibantu alat peraga. Dalam rangka meningkatkan daya tarik materi yang diajarkan, usaha yang dilakukan guru dengan menggunakan alat peraga dan menyediakan contoh dalam kehidupan sehari-hari yang dialami siswa.

Selain itu untuk anak autis, selaras dengan hasil penelitiannya Suharsiwi (2015) model pembelajaran keterampilan sosial dapat dijadikan model alternatif bagi pembelajaran keterampilan sosial untuk anak autis yang sebagian besar mengalami kesulitan berkomunikasi dan memerlukan bantuan untuk hidup mandiri. Dengan kata lain, mereka mengalami kesulitan dalam pemahaman, komunikasi/interaksi, dan kemandirian. Mereka membutuhkan bantuan dalam pendidikan, rekreasi, dan pekerjaan. Mereka tergantung pada orang lain dan harus diberi suatu kerangka eksternal dimana struktur dan organisasi membuat hidup mereka sedikit lebih jelas dan mudah (Suharsiwi, 2015). Berbagai upaya dilakukan guru untuk mengatasi hambatan terebut: misalnya menggunakan PPI, membuat media pembelajaran mandiri dan mempelajari berbagai metode terbaru yang dapat diterapkan dalam pembelajaran Bahasa Indonesia untuk anak autis (Suharsiwi, 2015).

Sedangkan menurut Pamuji (2014) mengatakan bahwa cara belajar anak autis berbeda dengan aktivitas belajar anak pada umumnya. Mereka memerlukan fasilitas khusus untuk bisa belajar (Pamuji, 2014). Penulisan makalah ini bertujuan mengidentifikasi media gambar dan menjelaskan cara menggunakan media tersebut agar dapat meningkatkan akvitas belajar anak autis dalam kelas (Pamuji, 2014). Media pembelajaran gambar merupakan media yang dapat 
memvisualisasikan informasi, pesan, nilai dan keterampilan kepada anak didik (Pamuji, 2014). Media gambar akan lebih efektif digunakan jika anak didik bertipe belajar visual (Pamuji, 2014). Di lapangan anak autis diketahui sebagai anak yang bertype belajar visual (Pamuji, 2014). Anak dapat memahami informasi, berbuat dan mengerjakan sesuatu seperti yang dilihatnya (Pamuji, 2014). Disamping itu anak autis tertarik pada objek berwarna, berbentuk dan bertekstur tertentu.Ketertarikan anak pada objek tersebut dapat dimanfaatkan dalam kegiatan pembelajaran dan mengarahkan kegiatan belajar (Pamuji, 2014).

\section{KESIMPULAN}

Proses pembelajaran adalah upaya yang dilakukan oleh individu dengan segala aktivitasnya baik membaca, meniru, melihat, dan berani mencoba hal-hal yang telah dipelajari dengan tujuan dapat memberikan tanggapan positif serta mendapatkan perubahan baik tingkah laku, cara berpikir, maupun pengetahuan dan keterampilannya. Kemampuan seorang anak dengan anak lainnya berbedabeda begitu pula dengan proses belajar yang tepat bagi mereka. Pada anak tunarungu sendiri proses belajar mereka lebih menggunakan media media tertentu seperti objek, gambar, video, ataupun tulisan. Mereka tidak akan dapat bisa memahami jika kita hanya menjelaskan suatu hal menggunakan kata kata saja, terlebih lagi jika cara bicara kita terlalu cepat bagi mereka. Terlepas dari semua itu, pada anak tunarungu kecerdasan intelektual mereka sama seperti anak pada umumnya. Meskipun kemampuan verbal anak tunarungu terganggu, tetapi tidak dengan kemampuan motorik mereka.

Berbeda halnya dengan anak autisme, pada anak autisme seringkali mereka memiliki gangguan pada mental, kemampuan verbal, serta kemampuan motorik mereka. Oleh karena itu, tujuan utama sekolah utama pada anak autisme bukan mengejar nilai atau target capaian pengetahuan tertentu, tetapi hanya agar mereka dapat belajar bersosialisai dan berinteraksi dengan orang lain. Hal inilah yang menyebabkan proses belajar anak autisme tidak sama dengan anak-anak lainnya. Jika anak pada umumnya menggunakan metode belajar menghapal atau sejenisnya guna meningkatkan pengetahuan akademik mereka, pada anak autisme metode belajar yang tepat adalah metode yang melibatkan emosi didalamnya 
sehingga dapat meningkatkan kemampuan mereka dalam berkomunikasi dan berinteraksi dengan orang lain.

\section{DAFTAR PUSTAKA}

Buli-Holmberg, J., \& Jeyaprathaban, S. (2016). Effective practice in inclusive and special needs education. International Journal of Special Education, 31(1), 119-134.

Darling-Hammond, L., Flook, L., Cook-Harvey, C., Barron, B., \& Osher, D. (2020). Implications for educational practice of the science of learning and development. Applied Developmental Science, 24(2), 97-140.

Depdiknas.(2004). Pedoman Penyelenggaraan Pendidikan Terpadu/Inklusi. Jakarta: DitPLB

Dermawan, O. (2013). Strategi pembelajaran bagi anak berkebutuhan khusus di slb. Psympathic: Jurnal Ilmiah Psikologi, 6(2), 886-897.

Handayani, Endang Sri (2017). "Peningkatan Pemahaman Dongeng Anak Tunarungu Melalui Simulation Based Learning." IJDS: INDONESIAN JOURNAL OF DISABILITY STUDIES 4.1 (2017): 9-15.

Khalil, M. K., \& Elkhider, I. A. (2016). Applying learning theories and instructional design models for effective instruction. Advances in physiology education, 40(2), 147-156.

Nugroho, A., \& Mareza, L. (2016). Model dan Strategi Pembelajaran Anak Berkebutuhan Khusus dalam Setting Pendidikan Inklusi. JURNAL PENDIDIKAN DASAR PERKHASA: Jurnal Penelitian Pendidikan Dasar, 2(2), 145-156.

Pamuji, P. (2014). Adaptasi Media Pembelajaran Gambar Untuk Meningkatkan Aktivitas Belajar Anak Autis. Jurnal Ortopedagogia, 1(2), 117-127.

Sarbani, S. (2014). Manajemen Pembelajaran Bahasa Indonesia Anak Tunarungu Slb Wiyata Dharma I Sleman. Jurnal Penelitian Ilmu Pendidikan UNY, 7(2), 124216.

Spears, Harold. (1955). Principles of Teaching. Printi Hall. New York.

Sudirman, S., Senjaya, A. J., \& SW, P. E. (2017). Analisis Gaya Belajar Siswa Tunagrahita Ringan Materi Perkalian di Sekolah dan di Rumah. Journal of Medives: Journal of Mathematics Education IKIP Veteran Semarang, 1(1), 1-8.

Diterbitkan oleh:

Universitas Wiralodra

Jln. Ir. H. Juanda Km 3 Indramayu, Jawa Barat 
Suharsiwi, S. (2015). Pengembangan Model Pembelajaran Keterampilan Sosial Anak Autis di Tk B. Jurnal Ilmiah Visi, 10(1), 1-8.

Wang, H. L. (2009). Should All Students with Special Educational Needs (SEN) Be Included in Mainstream Education Provision?--A Critical Analysis. International Education Studies, 2(4), 154-161. 